\title{
Appendiceal Adenocarcinoma Found by Surgery for Acute Appendicitis is Associated with Older Age - A Retrospective Cohort Study
}

\author{
Victor S. Alemany \\ Jacobi Medical Center \\ John P. Skendelas \\ Montefiore Medical Center https://orcid.org/0000-0002-3491-7568 \\ Vincent Au \\ Jacobi Medical Center \\ Devika Rao \\ Montefiore Medical Center \\ John McNelis \\ Jacobi Medical Center \\ Peter K. Kim ( $\square$ kim.peter.p01@gmail.com ) \\ Jacobi Medical Center
}

Research article

Keywords: acute appendicitis, adenocarcinoma, neuroendocrine tumor, mucinous neoplasm, emergency general surgery, acute care surgery

Posted Date: October 14th, 2020

DOl: https://doi.org/10.21203/rs.3.rs-90904/v1

License: (c) (i) This work is licensed under a Creative Commons Attribution 4.0 International License.

Read Full License 


\section{Abstract}

Background: Appendectomy for acute appendicitis is the most common procedure performed emergently by general surgeons in the United States. The current management of acute appendicitis is increasingly controversial as non-operative management gains favor as a primary therapy. Appendiceal neoplasms are found rarely and often as an incidental finding in the setting of appendectomy for acute appendicitis. Criteria and screening for appendiceal neoplasms are not standardized among surgical societies.

Methods: We reviewed electronic medical records for a nine-year period (2010-2018) of patients who underwent appendectomy in two municipal hospitals in The Bronx, New York City. The authors also examined patients undergoing appendectomy during the same time interval through a query of the National Surgical Quality Improvement Program (NSQIP) database.

Results: We found a $1.7 \%$ incidence of appendiceal neoplasms locally and a $0.53 \%$ incidence of appendiceal tumors in available national population sample. Both groups demonstrated an increased incidence of appendiceal carcinoma by age. This finding was most pronounced after the age of 40 in both local and national populations. In our study, the incidence of appendiceal tumors increased with each decade interval up to the age of 80 , and peaked at $2.1 \%$ in patients between 70 and 79 years.

Conclusions: We submit that the management of acute appendicitis involves a consideration of appendiceal neoplasm in patients over the age of 40 . This should be considered in the management of older patients with acute appendicitis before a decision to embark on non-operative therapy. If this is undertaken, interval appendectomy or further cancer screening and surveillance should be performed.

\section{Background}

The incidence of appendicitis in the US has been reported to be between 82 and 111 per 100,000 population per year, with a life-time risk of 1 in 15 (6.7\%)(1). Appendectomy for acute appendicitis is the most common emergency intra-abdominal operation performed by general surgeons, and approximately 300,000 appendectomies are performed annually in the United States alone (2). In recent years, there has been increased interest in non-operative management of acute appendicitis as first line therapy (3-6). A meta-analysis from Europe reported that the treatment of acute appendicitis was approached with antibiotic therapy in $40-45 \%$ of the patients compared to less than $5 \%$ in the United States $(7,8)$. This shift in clinical practice has raised concern regarding the risk of missing an appendiceal neoplasms in patients who receive non-operative therapy (9). While the overall incidence remains low, there are neither established criteria to determine which patients are eligible for medical management nor criteria for patients who may require oncologic surveillance after non-operative treatment for appendicitis. The aims of this study were 1) to determine first the incidence of appendiceal neoplasms in two urban municipal hospitals in the Bronx, New York City and 2) to compare these findings to those reported in the literature and the National Surgical Quality Improvement Program (NSQIP) database. 


\section{Methods}

In this retrospective cohort study, data were collected from the electronic medical records of all patients diagnosed with acute appendicitis in the period January, 2010 through December, 2018 in two Bronx municipal hospitals. Medical records were identified through ICD-9 codes for 'appendicitis": 540 (540.0, 540.1, 540.9), 541, 542; "appendectomy as an outpatient procedure": 44950, 44955, 44960, 44870, 44979, 44900, 44901; "appendectomy as an inpatient procedure": 45.72, 45.73, 47, 47.01, 47.09, 47.1, 47.11, $47.19,47.2,47.92,47.99$; "neoplasm of the appendix": 153.9 and 152.9; and the ICD 10 codes for "appendicitis" K35, K36, "other appendicitis" K37 and K38; "neoplasm of the appendix", "neoplasm of the intestinal tract", "small intestine and colon unspecified" C17.9, C18.9, C26.0 and C18.1 and for "appendectomy": 0DTJ0ZZ, 0DTJ4ZZ, 0DTJ7ZZ, 0DTJ8ZZ. Records were further confirmed with an institutional Tumor Registry and Pathology database to ensure inclusion of all malignant cases. All 2131 pathology reports were reviewed to evaluate for neoplasms in appendectomy specimens. Data acquitted included age at diagnosis, sex, prior colonoscopy records, radiographic findings, as well as final pathology and oncologic outcomes.

Continuous variables were expressed as means with $95 \%$ confidence intervals $(\mathrm{Cl})$ or median with interquartile range (IQR). Categorical variables were described with number counts and percentages. Continuous variables were compared using independent $t$ test or Mann-Whitney $\mathrm{U}$ test for normal and non-normal predictors, respectively. Categorical variables were compared using Chi-square tests. A pvalue less than 0.05 was considered statistically significant. All analyses were performed using SPSS Version 25.0 (IBM Corp, Armonk, NY, USA). All data collection and chart review were performed with approval by the hospital's Institutional Review Board (IRB) of the Albert Einstein College of Medicine (IRB Protocol \#2017-7530).

The National Surgical Quality Improvement Program (NSQIP) personal use file database was queried using the ICD-9 codes listed above in the time interval of May 1, 2010 to December 31, 2018. During this time period there were over 2.8 million patients in the database. All patients who had undergone appendectomy were then queried for appendiceal neoplasm. Cases of appendiceal neoplasm were then broken down by age, type of procedure, and pathologic diagnosis. In the database there were only three pathologies of appendiceal neoplasm specified: adenocarcinoma, malignant carcinoid, and unspecified. Cases with benign pathology after appendectomies were excluded from the analysis.

\section{Results}

A total of 2131 medical charts from patients diagnosed with acute appendicitis were reviewed in two municipal hospitals using the electronic medical records from 2010 through 2018. At these institutions, 1996 patients $(93.7 \%)$ underwent operative treatment for acute appendicitis, with 1108 patients (55.5\% of total surgeries) undergoing laparoscopic appendectomy, 854 for open surgery $(42.8 \%)$ and $33(1.7 \%)$ who underwent conversion from laparoscopic to open approach. From the operative cohort, 34 patients were diagnosed with appendiceal neoplasm after the pathologic study of the removed appendix which 
reflected an incidence of $1.7 \%$ in this study population over nine years (Fig. 1). The mean age of the neoplasm cohort was 48.6 years $(95 \% \mathrm{Cl}$ [42.1-55.2]), with approximately 2:1, female to male ratio (65.7\% female). Remaining demographics and clinical factors are presented by benign (low-grade appendiceal mucinous neoplasm or LAMN, neuroendocrine), or malignant or disseminated (adenocarcinoma, metastatic) disease in Table 1. Of note, all neuroendocrine tumors were Grade 1 and categorized as benign.

Table 1

Demographics

\begin{tabular}{|c|c|c|c|}
\hline & $\begin{array}{l}\text { Benign* } \\
(n=23)\end{array}$ & $\begin{array}{l}\text { Malignant / Disseminated } \\
(n=11)\end{array}$ & P-value \\
\hline Age, years $(95 \% \mathrm{Cl})$ & $43.7[35.9-51.5]$ & $59.1[46.5-71.7]$ & 0.035 \\
\hline Female sex (\%) & $16(69.6)$ & $7(63.6)$ & 1.000 \\
\hline Previous colonoscopy (\%) & $7(30.4)$ & $3(27.3)$ & 1.000 \\
\hline Imaging size (cm) - median (IQR) & $1.2(1.0)$ & $1.3(0.6)$ & 0.637 \\
\hline Emergency department presentation (\%) & $19(82.6)$ & $10(90.9)$ & 0.797 \\
\hline Operative intervention (\%) & & & 0.525 \\
\hline Open & $9(39.1)$ & $6(54.5)$ & - \\
\hline Laparoscopic & $13(56.5)$ & $4(36.4)$ & - \\
\hline Converted & $1(4.3)$ & $1(9.1)$ & - \\
\hline \multicolumn{4}{|l|}{ IQR - interquartile range } \\
\hline \multicolumn{4}{|c|}{$\begin{array}{l}\text { *Patients with appendectomy specimen pathology consistent with low-grade appendiceal mucinous } \\
\text { neoplasm or neuroendocrine tumors were defined as "benign." Patients with clinical or pathological } \\
\text { evidence of appendiceal adenocarcinoma or metastatic disease were defined as } \\
\text { malignant/disseminated. }\end{array}$} \\
\hline \multicolumn{4}{|c|}{ **Complicated cases included peritonitis, pneumoperitoneum, perforation, abscess, or phlegmon } \\
\hline
\end{tabular}

The entire series of patients with appendiceal neoplasms are presented in Table 2 with associated age at diagnosis, appendiceal size on imaging, surgical approach, pathology, and stage. The final pathology revealed 8 cases of adenocarcinoma ( $0.4 \%$ of appendectomy specimens), 14 neuroendocrine tumors $(0.7 \%), 9$ low-grade appendiceal mucinous neoplasms (LAMN, $0.4 \%$ ), and three cases evident of metastatic disease $(0.2 \%)$. Twenty-six $(74.3 \%)$ of the patients were 40 years or older at the time of diagnosis. Moreover, the diameter of the appendix was greater or equal to $1.0 \mathrm{~cm}$ on pre-operative imaging in 28 of $34(82.3 \%)$ of patients with appendiceal cancer. All patients with LAMN $(n=9)$ had an appendiceal diameter greater than $1.0 \mathrm{~cm}$. A representation of patients divided by type of neoplasm and 
age is presented in Fig. 2. Adenocarcinoma only appeared in patients older than the age of 40 in the local cohort. Older age was associated with malignant or disseminated disease: 59.1 [46.5-71.7] vs. 43.7 [35.9-51.5] years $(p=0.035$; Table 1$)$. 
Table 2

Summary of Appendiceal Neoplasms

\begin{tabular}{|c|c|c|c|c|c|}
\hline $\begin{array}{l}\text { Patient } \\
\text { ID }\end{array}$ & $\begin{array}{l}\text { Age at } \\
\text { Presentation } \\
\text { (years) }\end{array}$ & $\begin{array}{l}\text { Appendiceal } \\
\text { Imaging } \\
\text { Size }(\mathrm{cm})\end{array}$ & Pathology & $\begin{array}{l}\text { Stage } \\
\text { (TNM) }\end{array}$ & Surgical Procedure \\
\hline 1 & 73 & 3.1 & Adenocarcinoma & $\begin{array}{l}\text { IIA } \\
\text { (T3, } \\
\text { N0, } \\
\text { M0) }\end{array}$ & Open right hemicolectomy \\
\hline 2 & 67 & 3.0 & Adenocarcinoma & IV & $\begin{array}{l}\text { Diagnostic laparoscopy with } \\
\text { appendectomy, omental and } \\
\text { peritoneal biopsy }\end{array}$ \\
\hline 3 & 66 & 0.8 & Adenocarcinoma & $\begin{array}{l}\text { I } \\
\text { (T2, } \\
\text { N0, } \\
\text { M0) }\end{array}$ & Open right hemicolectomy \\
\hline 4 & 63 & 1.2 & Adenocarcinoma & $\begin{array}{l}\text { IIA } \\
\text { (T3, } \\
\text { N0, } \\
\text { M0) }\end{array}$ & Open right hemicolectomy \\
\hline 5 & 62 & 0.5 & Adenocarcinoma & $\begin{array}{l}\text { IIA } \\
\text { (T3, } \\
\text { NO, } \\
\text { M0) }\end{array}$ & $\begin{array}{l}\text { Laparoscopic } \\
\text { appendectomy converted to } \\
\text { open right hemicolectomy } \\
\text { with partial omentectomy }\end{array}$ \\
\hline 6 & 82 & 1.4 & Adenocarcinoma & $\begin{array}{l}\text { IV } \\
(\mathrm{T} 4, \\
\text { N2, } \\
\text { M1) }\end{array}$ & Open right hemicolectomy \\
\hline 7 & 54 & 1.4 & Adenocarcinoma & $\begin{array}{l}\text { IIA } \\
\text { (T3, } \\
\text { N0, } \\
\text { M0) }\end{array}$ & $\begin{array}{l}\text { Laparoscopic } \\
\text { appendectomy with interval } \\
\text { open right hemicolectomy }\end{array}$ \\
\hline 8 & 49 & 1.3 & Adenocarcinoma & $\begin{array}{l}\text { IV } \\
\text { (T3, } \\
\text { N2, } \\
\text { M1) }\end{array}$ & Open right hemicolectomy \\
\hline
\end{tabular}

LAMN - low-grade appendiceal mucinous neoplasm 


\begin{tabular}{|c|c|c|c|c|c|}
\hline $\begin{array}{l}\text { Patient } \\
\text { ID }\end{array}$ & $\begin{array}{l}\text { Age at } \\
\text { Presentation } \\
\text { (years) }\end{array}$ & $\begin{array}{l}\text { Appendiceal } \\
\text { Imaging } \\
\text { Size }(\mathrm{cm})\end{array}$ & Pathology & $\begin{array}{l}\text { Stage } \\
\text { (TNM) }\end{array}$ & Surgical Procedure \\
\hline 9 & 23 & 1.3 & Neuroendocrine & $\begin{array}{l}\text { I } \\
\text { (T1, } \\
\text { N0, } \\
\text { M0) }\end{array}$ & $\begin{array}{l}\text { Laparoscopic } \\
\text { appendectomy }\end{array}$ \\
\hline 10 & 71 & 1.2 & Neuroendocrine & $\begin{array}{l}\text { I } \\
\text { (T1, } \\
\text { N0, } \\
\text { M0) }\end{array}$ & $\begin{array}{l}\text { Open ileocecectomy with } \\
\text { ileostomy }\end{array}$ \\
\hline 11 & 56 & 0.3 & Neuroendocrine & $\begin{array}{l}\text { II } \\
\text { (T3, } \\
\text { NO, } \\
\text { MO) }\end{array}$ & $\begin{array}{l}\text { Laparoscopic } \\
\text { appendectomy }\end{array}$ \\
\hline 12 & 53 & 1.1 & Neuroendocrine & $\begin{array}{l}\text { I } \\
\text { (T1, } \\
\text { N0, } \\
\text { M0) }\end{array}$ & $\begin{array}{l}\text { Laparoscopic } \\
\text { appendectomy }\end{array}$ \\
\hline 13 & 47 & 1.5 & Neuroendocrine & $\begin{array}{l}\text { I } \\
\text { (T1, } \\
\text { N0, } \\
\text { M0) }\end{array}$ & $\begin{array}{l}\text { Laparoscopic } \\
\text { appendectomy }\end{array}$ \\
\hline 14 & 47 & 0.7 & Neuroendocrine & $\begin{array}{l}\text { III } \\
\text { (T4, } \\
\text { N0, } \\
\text { M0) }\end{array}$ & $\begin{array}{l}\text { Laparoscopic } \\
\text { appendectomy }\end{array}$ \\
\hline 15 & 46 & 1.1 & Neuroendocrine & $\begin{array}{l}\text { I } \\
\text { (T1, } \\
\text { N0, } \\
\text { M0) }\end{array}$ & $\begin{array}{l}\text { Laparoscopic } \\
\text { appendectomy }\end{array}$ \\
\hline 16 & 40 & 0.9 & Neuroendocrine & $\begin{array}{l}\text { I } \\
\text { (T1, } \\
\text { N0, } \\
\text { M0) }\end{array}$ & Open appendectomy \\
\hline
\end{tabular}

LAMN - low-grade appendiceal mucinous neoplasm 


\begin{tabular}{|c|c|c|c|c|c|}
\hline $\begin{array}{l}\text { Patient } \\
\text { ID }\end{array}$ & $\begin{array}{l}\text { Age at } \\
\text { Presentation } \\
\text { (years) }\end{array}$ & $\begin{array}{l}\text { Appendiceal } \\
\text { Imaging } \\
\text { Size }(\mathrm{cm})\end{array}$ & Pathology & $\begin{array}{l}\text { Stage } \\
\text { (TNM) }\end{array}$ & Surgical Procedure \\
\hline 17 & 28 & 1.0 & Neuroendocrine & $\begin{array}{l}\text { I } \\
\text { (T1, } \\
\text { No, } \\
\text { MO) }\end{array}$ & Open appendectomy \\
\hline 18 & 26 & 1.1 & Neuroendocrine & $\begin{array}{l}\text { I } \\
\text { (T1, } \\
\text { N0, } \\
\text { M0) }\end{array}$ & Open appendectomy \\
\hline 19 & 25 & 1.4 & Neuroendocrine & $\begin{array}{l}\text { I } \\
\text { (T1, } \\
\text { No, } \\
\text { MO) }\end{array}$ & Open appendectomy \\
\hline 20 & 23 & 1.1 & Neuroendocrine & $\begin{array}{l}\text { I } \\
\text { (T2, } \\
\text { N0, } \\
\text { M0) }\end{array}$ & Open appendectomy \\
\hline 21 & 10 & 1.1 & Neuroendocrine & $\begin{array}{l}\text { I } \\
\text { (T1, } \\
\text { No, } \\
\text { MO) }\end{array}$ & $\begin{array}{l}\text { Laparoscopic } \\
\text { appendectomy }\end{array}$ \\
\hline 22 & 9 & 1.1 & Neuroendocrine & $\begin{array}{l}\text { I } \\
\text { (T1, } \\
\text { No, } \\
\text { MO) }\end{array}$ & $\begin{array}{l}\text { Laparoscopic } \\
\text { appendectomy }\end{array}$ \\
\hline 23 & 75 & 3.7 & LAMN & - & $\begin{array}{l}\text { Laparoscopic } \\
\text { appendectomy }\end{array}$ \\
\hline 24 & 64 & 4.5 & LAMN & - & $\begin{array}{l}\text { Laparoscopic } \\
\text { appendectomy }\end{array}$ \\
\hline 25 & 58 & 1.5 & LAMN & - & $\begin{array}{l}\text { Laparoscopic } \\
\text { appendectomy }\end{array}$ \\
\hline 26 & 56 & 2.5 & LAMN & - & $\begin{array}{l}\text { Laparoscopic } \\
\text { appendectomy }\end{array}$ \\
\hline 27 & 55 & 1.5 & LAMN & - & $\begin{array}{l}\text { Laparoscopic } \\
\text { appendectomy }\end{array}$ \\
\hline
\end{tabular}

LAMN - low-grade appendiceal mucinous neoplasm 


\begin{tabular}{|c|c|c|c|c|c|}
\hline $\begin{array}{l}\text { Patient } \\
\text { ID }\end{array}$ & $\begin{array}{l}\text { Age at } \\
\text { Presentation } \\
\text { (years) }\end{array}$ & $\begin{array}{l}\text { Appendiceal } \\
\text { Imaging } \\
\text { Size }(\mathrm{cm})\end{array}$ & Pathology & $\begin{array}{l}\text { Stage } \\
\text { (TNM) }\end{array}$ & Surgical Procedure \\
\hline 28 & 54 & 4.5 & LAMN & - & $\begin{array}{l}\text { Laparoscopic } \\
\text { appendectomy converted to } \\
\text { open right hemicolectomy }\end{array}$ \\
\hline 29 & 50 & 1.2 & LAMN & - & $\begin{array}{l}\text { Open right hemicolectomy } \\
\text { with resection of terminal } \\
\text { ileum and ileocolic } \\
\text { anastomosis }\end{array}$ \\
\hline 30 & 47 & 5.5 & LAMN & - & $\begin{array}{l}\text { Laparoscopic } \\
\text { appendectomy }\end{array}$ \\
\hline 31 & 42 & 2.1 & LAMN & - & Open appendectomy \\
\hline 32 & 17 & 0.9 & $\begin{array}{l}\text { Metastatic } \\
\text { peritoneal } \\
\text { mesothelioma }\end{array}$ & IV & $\begin{array}{l}\text { Laparoscopic } \\
\text { appendectomy }\end{array}$ \\
\hline 33 & 78 & 1.0 & $\begin{array}{l}\text { Metastatic } \\
\text { breast } \\
\text { adenocarcinoma }\end{array}$ & IV & Open right hemicolectomy \\
\hline 34 & 39 & 1.5 & $\begin{array}{l}\text { Metastatic } \\
\text { gastric cancer }\end{array}$ & IV & $\begin{array}{l}\text { Laparoscopic } \\
\text { appendectomy }\end{array}$ \\
\hline
\end{tabular}

The National Surgical Quality Improvement Program (NSQIP) database was queried between 2010 and 2018. A total of 154,596 appendectomies performed in adult (age $\geq 18$ years) patients were identified, which included 812 cases of appendiceal cancer (for an incidence of $0.53 \%$ ). The incidence of appendiceal tumors stratified by age are summarized in Fig. 3. The combined incidence of appendiceal neoplasms identified in these data are $0.4 \%, 0.8 \%, 1.6 \%, 2.1 \%$, and $1.6 \%$ respectively for age $40-49,50-$ $59,60-69,70-79$, and $>80$. For patients older than 40 years, $1 \%$ of appendectomy specimens demonstrated an appendiceal neoplasm. From the 812 appendiceal neoplasms, 681 adenocarcinomas of the appendix (0.4\%) were identified. For these patients, 290 underwent appendectomy and 524 underwent colectomy; 133 patients underwent both procedures.

\section{Discussion}

In this study we reviewed 2131 cases of acute appendicitis in two municipal hospitals. The incidence of adenocarcinoma increased with age greater than 40 at our institutions, while cases of adenocarcinoma were reported in patients under 40 years in the NSQIP analysis. These data concur with a similar NSQIP analysis performed by Lu, et a/ between 2016 and 2017. These results were in agreement with those 
established in prior reports that support a significant association between increased risk of malignancy and increasing age in patients who have undergone surgical appendectomy for presumed appendicitis (10). The rate of appendectomy at Jacobi Medical Center and North Central Bronx Hospital for acute appendicitis was $94 \%$, which also matched the United States NSQIP rate of $95 \%$. The rate of appendiceal cancer at Jacobi and North Central Bronx Hospital of $1.7 \%$ was higher than the observed NSQIP rate of $0.53 \%$ for appendiceal cancer in acute appendicitis.

Although the cause of appendicitis is unknown, the incidence of appendicitis has increased in industrialized countries. In the setting of a progressively aging population, there is an observed increase in appendicitis in older adults. The management patterns of acute appendicitis are also evolving. Many patients are managed non-operatively(1). Over the last several years, numerous studies have determined safety and efficacy of non-operative treatment with specific indications $(1,2,6,11-20)$. Healthcare providers have been eager to adapt this new modality without consideration for possible long-term outcomes, and oncologic ramification. To date, the only gold standard confirmatory test for appendiceal cancer is appendectomy that is usually performed for the presentation of acute appendicitis (21-23). In a recent prospective study of acute complex appendicitis, patients with complicated appendicitis who underwent either surveillance or interval appendectomy were found to have an exceedingly high rate of malignancy that even resulted in premature discontinuation of a prospective study $(10,24-26)$. Our findings corroborate recent findings in prospectively collected data, analyzed post-hoc, from the MUSTANG trial (27). Taken together we concur that age older than 40 must be considered a risk factor for malignancy when considering appendectomy at initial presentation or at a later date $(27,28)$.

Appendiceal neoplasms are a heterogeneous entity that escape straightforward classification or management (29-31). Further study of these tumors in the acute setting is required to adequately screen patients who may not be eligible for medical management or whose atypical presentation may highlight the need for further oncologic workup prior to surgical intervention.

Our local study was limited by its retrospective design and review of patient data from a now unmaintained, older electronic medical record. In the emergency surgery setting, patient follow-up was poor. Our municipal hospital system also serves underrepresented and an economically disadvantaged patient population with limited adherence in all surgical settings. Furthermore, the practice patterns at our institution, with inclusion of earlier data, reflected a surgical practice pattern that may be limited at other centers, especially outside the United States.

Analysis of the NSQIP data demonstrated that the incidence of appendiceal neoplasm was higher in older adults, with a marked increase after 50 years. Nonetheless, this incidence was lower than that observed in our urban, Bronx-based population (0.53\% vs. $1.7 \%)$. There are several explanations for this discrepancy. NSQIP does not capture every case of appendicitis. This leaves open the possibility that cases of appendicitis were missed. This deficiency combined with the larger sample size may lead to a decrease in relative percentages of appendicitis in the NSQIP sample. Another point of possible discrepancy involved the pathologic diagnosis of appendiceal cancer. In the local group, anatomic pathology was performed 
and reviewed by one group. In NSQIP the data input was entered at the time of initial diagnosis based on a pathology report. It is possible that diagnostic criteria may vary from facility to facility across a national database. Regardless, the overall trends were similar. The incidence of appendiceal neoplasm, in particular appendiceal adenocarcinoma, increased with age and highlighted the need to consider the possibility of underlying malignancy in acute appendicitis in adults over the age of 40 .

\section{Conclusions}

Appendiceal neoplasms are a heterogeneous group of diseases that vary significantly in oncologic outcomes and are often diagnosed in the setting of acute appendicitis. Age greater than 40 years and female gender were more common in our patients with appendiceal neoplasms. General and acute care surgeons should remain vigilant in recognition of these diseases and ensure appropriate surgical care, oncologic management, and surveillance are maintained outside of the emergency setting.

\section{Abbreviations}

NSQIP: National Surgical Quality Improvement Program

Cl: confidence interval

IQR: interquartile range

LAMN: low-grade appendiceal mucinous neoplasm

\section{Declarations}

\section{Ethics approval}

This study received ethics approval by the Albert Einstein College of Medicine Internal Review Board prior to data collection and analysis.

\section{Consent for publication}

Not applicable

\section{Availability of supporting data}

De-identified patient data are available for external review upon request. Requests for identified patient data will be submitted to the Internal Review Board of Albert Einstein College of Medicine for consideration.

\section{Competing interests}

The authors declare that they have no competing interests. 


\section{Funding}

Not applicable.

\section{Author contribution}

Victor S. Alemany and John P. Skendelas are both co-first authors of this manuscript and contributed equally in the collection, categorization, organization, and analysis of the data and wrote the manuscript with assistance and supervision of Peter K. Kim. Vincent Au contributed to the writing of the manuscript and data collection. Devika Rao conceived the design and collection of the data. John McNelis obtained the National Surgery Quality Improvement Program (NSQIP) data and helped with the manuscript preparation. Peter K. Kim conceived the original idea, supervised manuscript preparation, and took the lead of the project.

\section{Acknowledgements}

We thank the Physician Affiliate Group of New York (PAGNY) Health and Research Foundation who supported this project and is committed to enhancing health on all of New York City's diverse communities. We also thank Sherrie R. White, MD and Joanne Stern, who aided in data collection.

\section{References}

1. Ferris M, Quan S, Kaplan BS, Molodecky N, Ball CG, Chernoff GW, et al. The global incidence of appendicitis: a systematic review of population-based studies. Annals of surgery. 2017;266(2):23741.

2. Mason RJ. Surgery for appendicitis: is it necessary? Surg Infect (Larchmt). 2008;9(4):481-8.

3. Di Saverio S, Sibilio A, Giorgini E, Biscardi A, Villani S, Coccolini F, et al. The NOTA Study (Non Operative Treatment for Acute Appendicitis): prospective study on the efficacy and safety of antibiotics (amoxicillin and clavulanic acid) for treating patients with right lower quadrant abdominal pain and long-term follow-up of conservatively treated suspected appendicitis. Ann Surg. 2014;260(1):109-17.

4. Kadera SP, Mower WR, Krishnadasan A, Talan DA. Patient perspectives on antibiotics for appendicitis at one hospital. J Surg Res. 2016;201(2):253-7.

5. Loftus TJ, Raymond SL, Sarosi GA, Jr., Croft CA, Smith RS, Efron PA, et al. Predicting appendiceal tumors among patients with appendicitis. J Trauma Acute Care Surg. 2017;82(4):771-5.

6. McCutcheon BA, Chang DC, Marcus LP, Inui T, Noorbakhsh A, Schallhorn C, et al. Long-term outcomes of patients with nonsurgically managed uncomplicated appendicitis. J Am Coll Surg. 2014;218(5):905-13.

7. Kessler U, Mosbahi S, Walker B, Hau EM, Cotton M, Peiry B, et al. Conservative treatment versus surgery for uncomplicated appendicitis in children: a systematic review and meta-analysis. Arch Dis Child. 2017;102(12):1118-24. 
8. Huang L, Yin Y, Yang L, Wang C, Li Y, Zhou Z. Comparison of Antibiotic Therapy and Appendectomy for Acute Uncomplicated Appendicitis in Children: A Meta-analysis. JAMA Pediatr. 2017;171(5):42634.

9. Davidson GH, Flum DR, Talan DA, Kessler LG, Lavallee DC, Bizzell BJ, et al. Comparison of Outcomes of antibiotic Drugs and Appendectomy (CODA) trial: a protocol for the pragmatic randomised study of appendicitis treatment. BMJ Open. 2017;7(11):e016117.

10. Lu P, McCarty JC, Fields AC, Lee KC, Lipsitz SR, Goldberg JE, et al. Risk of appendiceal cancer in patients undergoing appendectomy for appendicitis in the era of increasing nonoperative management. Journal of surgical oncology. 2019;120(3):452-9.

11. Styrud J, Eriksson S, Nilsson I, Ahlberg G, Haapaniemi S, Neovius G, et al. Appendectomy versus antibiotic treatment in acute appendicitis. a prospective multicenter randomized controlled trial. World journal of surgery. 2006;30(6):1033-7.

12. Vons C, Barry C, Maitre S, Pautrat K, Leconte M, Costaglioli B, et al. Amoxicillin plus clavulanic acid versus appendicectomy for treatment of acute uncomplicated appendicitis: an open-label, noninferiority, randomised controlled trial. Lancet. 2011;377(9777):1573-9.

13. Teixeira PG, Demetriades D. Appendicitis: changing perspectives. Adv Surg. 2013;47:119-40.

14. Sippola S, Gronroos J, Tuominen R, Paajanen H, Rautio T, Nordstrom P, et al. Economic evaluation of antibiotic therapy versus appendicectomy for the treatment of uncomplicated acute appendicitis from the APPAC randomized clinical trial. Br J Surg. 2017;104(10):1355-61.

15. Sippola S, Grönroos J, Sallinen V, Rautio T, Nordström P, Rantanen T, et al. A randomised placebocontrolled double-blind multicentre trial comparing antibiotic therapy with placebo in the treatment of uncomplicated acute appendicitis: APPAC III trial study protocol. BMJ open. 2018;8(11).

16. Simillis C, Symeonides P, Shorthouse AJ, Tekkis PP. A meta-analysis comparing conservative treatment versus acute appendectomy for complicated appendicitis (abscess or phlegmon). Surgery. 2010;147(6):818-29.

17. Salminen P, Tuominen R, Paajanen $H$, Rautio T, Nordström P, Aarnio M, et al. Five-year follow-up of antibiotic therapy for uncomplicated acute appendicitis in the APPAC randomized clinical trial. Jama. 2018;320(12):1259-65.

18. Salminen P, Paajanen $H$, Rautio T, Nordstrom P, Aarnio M, Rantanen T, et al. Antibiotic Therapy vs Appendectomy for Treatment of Uncomplicated Acute Appendicitis: The APPAC Randomized Clinical Trial. JAMA. 2015;313(23):2340-8.

19. Haijanen J, Sippola S, Grönroos J, Rautio T, Nordström P, Rantanen T, et al. Optimising the antibiotic treatment of uncomplicated acute appendicitis: a protocol for a multicentre randomised clinical trial (APPAC II trial). BMC surgery. 2018;18(1):117.

20. Prechal D, Damirov F, Grilli M, Ronellenfitsch U. Antibiotic therapy for acute uncomplicated appendicitis: a systematic review and meta-analysis. International journal of colorectal disease. 2019;34(6):963-71. 
21. Talan DA. Cancer of the appendix and nonoperative treatment of appendicitis shared decision making. Journal of surgical oncology. 2019;120(6):1060-1.

22. Seawell J, Sciarretta JD, Pahlkotter M, Muertos K, Onayemi A, Davis JM. The Understated Malignancy Potential of Nonoperative Acute Appendicitis. Am Surg. 2019;85(7):712-6.

23. Mällinen J, Rautio T, Grönroos J, Rantanen T, Nordström P, Savolainen H, et al. Risk of appendiceal neoplasm in periappendicular abscess in patients treated with interval appendectomy vs follow-up with magnetic resonance imaging: 1-year outcomes of the peri-appendicitis acuta randomized clinical trial. JAMA surgery. 2019;154(3):200-7.

24. Mallinen J, Rautio T, Gronroos J, Rantanen T, Nordstrom P, Savolainen $\mathrm{H}$, et al. Risk of Appendiceal Neoplasm in Periappendicular Abscess in Patients Treated With Interval Appendectomy vs Follow-up With Magnetic Resonance Imaging: 1-Year Outcomes of the Peri-Appendicitis Acuta Randomized Clinical Trial. JAMA surgery. 2019;154(3):200-7.

25. Limaiem F, Arfa N, Marsaoui L, Bouraoui S, Lahmar A, Mzabi S. Unexpected Histopathological Findings in Appendectomy Specimens: a Retrospective Study of 1627 Cases. Indian J Surg. 2015;77(Suppl 3):1285-90.

26. Lietzen E, Gronroos JM, Mecklin JP, Leppaniemi A, Nordstrom P, Rautio T, et al. Appendiceal neoplasm risk associated with complicated acute appendicitis-a population based study. International journal of colorectal disease. 2019;34(1):39-46.

27. Yeh DD, Eid Al, Young KA, Wild J, Kaafarani HMA, Ray-Zack M, et al. Multicenter Study of the Treatment of Appendicitis in America: Acute, Perforated, and Gangrenous (MUSTANG), an EAST Multicenter Study. Ann Surg. 2019.

28. Naar L, Kim P, Byerly S, Vasileiou G, Zhang H, Yeh DD, et al. Increased risk of malignancy for patients older than 40 years with appendicitis and an appendix wider than $10 \mathrm{~mm}$ on computed tomography scan: A post hoc analysis of an EAST multicenter study. Surgery. 2020.

29. Wright GP, Mater ME, Carroll JT, Choy JS, Chung MH. Is there truly an oncologic indication for interval appendectomy? American journal of surgery. 2015;209(3):442-6.

30. West NE, Wise PE, Herline AJ, Muldoon RL, Chopp WV, Schwartz DA. Carcinoid tumors are 15 times more common in patients with Crohn's disease. Inflamm Bowel Dis. 2007;13(9):1129-34.

31. Todd RD, Sarosi GA, Nwariaku F, Anthony T. Incidence and predictors of appendiceal tumors in elderly males presenting with signs and symptoms of acute appendicitis. The American journal of surgery. 2004;188(5):500-4.

\section{Figures}




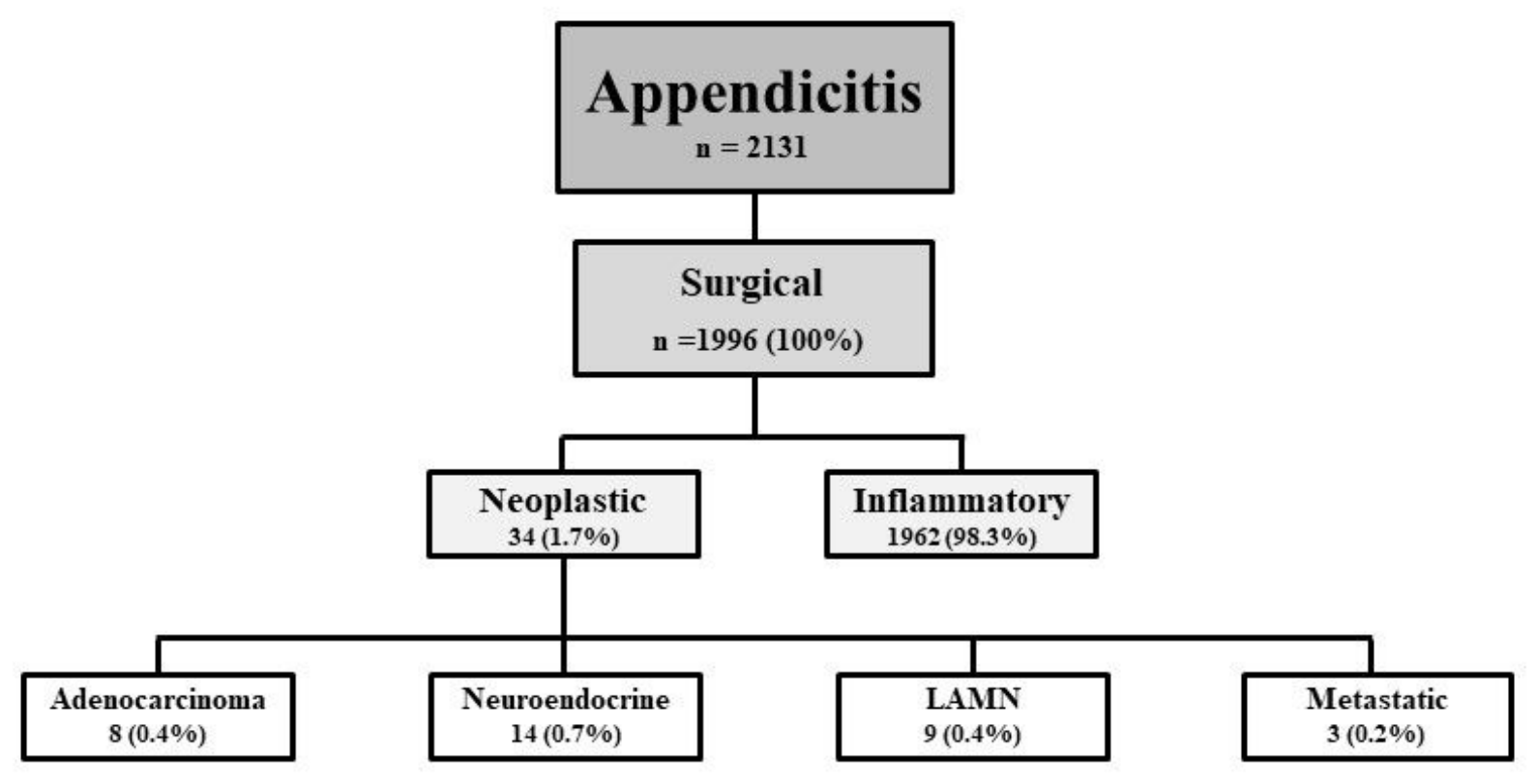

\section{Figure 1}

The total number of local cases of appendicitis and those managed surgically reviewed from two Bronx municipal hospitals for the period 2010 through 2018. The number of cases found to be appendiceal cancers are further categorized into adenocarcinoma, neuroendocrine, low grade appendiceal mucinous neoplasm (LAMN), and metastatic cancer. 
8

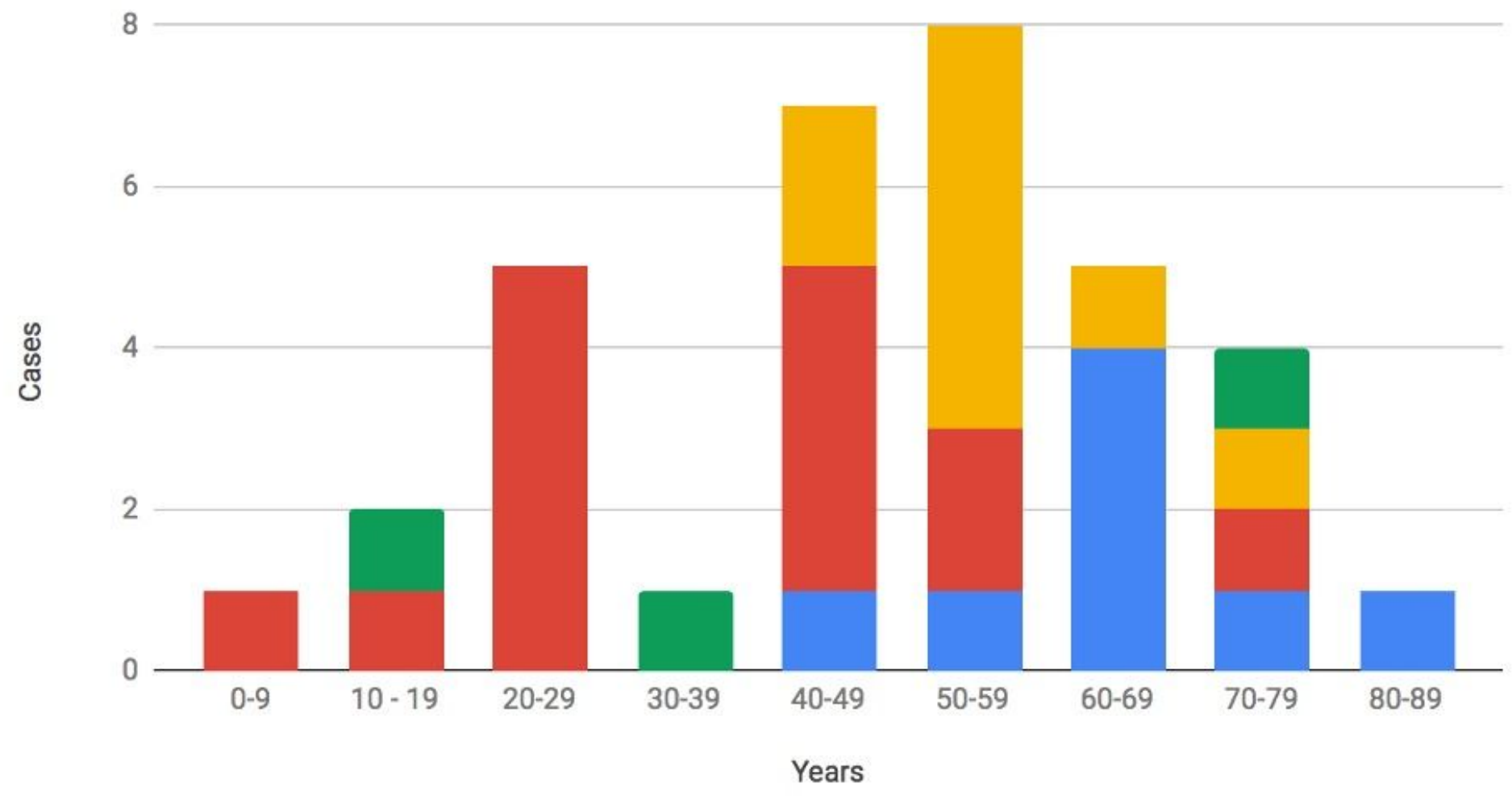

\section{Figure 2}

The incidence of adenocarcinoma, neuroendocrine, low grade appendiceal mucinous neoplasm (LAMN), and metastatic cancer from two Bronx municipal hospitals for the period 2010 through 2018 categorized into ten-year age groups. 


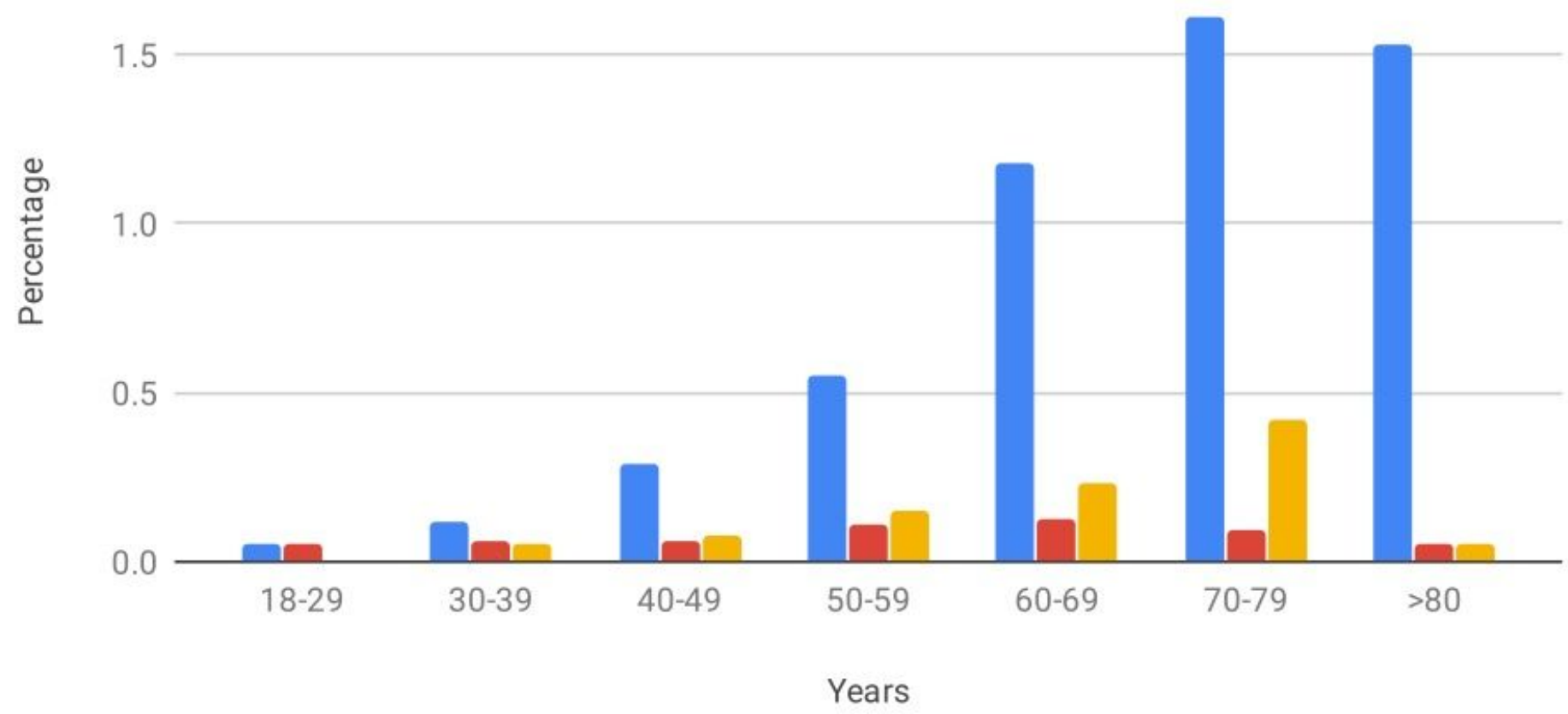

\section{Figure 3}

The incidence of adenocarcinoma, neuroendocrine, low grade appendiceal mucinous neoplasm (LAMN), and metastatic cancer obtained from the National Surgical Quality Improvement Program (NSQIP) database from 2010 to 2018 categorized into ten year age groups. 